\title{
Factors Impacting the Physical Function of Older Adults in Korean Long-Term Care Hospitals
}

\author{
Lee, Ji-Yun ${ }^{1} \cdot$ Kim, Eun-Young ${ }^{2} \cdot$ Cho, Eunhee ${ }^{3}$ \\ ${ }^{1}$ Associate Professor, Department of Nursing, Kangwon National University, Chuncheon \\ ${ }^{2}$ Associate Professor, Department of Nursing, Dong-A University, Busan \\ ${ }^{3}$ Assistant Professor, Nursing Policy Research Institute, College of Nursing, Yonsei University, Seoul, Korea
}

\begin{abstract}
Purpose: This study was conducted to examine activities of daily living (ADL) of older adults admitted to Korean long-term care hospitals (LTCHs), and to explore the patient and organizational factors that have an impact on the ADL of this population. Methods: A secondary analysis of the Korean minimum data set (K-MDS) of patients $(N=14,369)$ and of the profiles of LTCHs ( $N=358$ ) from the Health Insurance Review and Assessment Service was done between January and July 2008. The outcome variable was ADL score 6 months after baseline assessment. Multi-level linear regression was employed to explore the patient and organizational factors that affected ADL scores. Results: Of the patients, $45.4 \%$ had a baseline ADL score of between 31 and 40, with a score of 40 indicating that the patient was entirely dependent for all items. None of the organizational characteristics were significantly associated with effects on the ADLs of older adults who had been in a LTHC for at least 6 months. However, patient characteristics, such as age, baseline ADL, frequency of physical therapy, urinary incontinence, fecal incontinence, pressure ulcers, and having a tube or catheter, were significantly associated with ADL 6 months after baseline. Conclusion: In order to maintain and improve the ADL of older adults in LTCHs, we should develop strategies to prevent urinary and fecal incontinence, pressure ulcers, unnecessary tubes or catheters, providing adequate physical therapy. Additional studies should include more detailed information regarding nursing staff, including RN hours for direct care, education level and turnover.
\end{abstract}

Key words: Activities of daily living, Long-term care, Nursing staff

\section{INTRODUCTION}

The population of South Korea is aging rapidly. The proportion of adults aged 65 or over was $11.3 \%$ in 2010, and is predicted to reach $38.2 \%$ by 2050 (Korea National Statistical Office, 2011). According to data from the Korea Development Institute, 10.2 \% of Korea's older adults want long-term care (Korea Development Institute, 2010), and this figure will rapidly increase as the proportion of older adults in the general population increases.

Activities of daily living (ADL) is an important factor to consider when planning and providing long-term care for an elderly population (Morris, Murphy, \& Nonemaker, 2004). Dependence in ADL can lead to frailty, isolation, decreased self-esteem, and loss of control (Morris et al.). However, dependence in ADL is a common problem in patients admitted to long-term care institutions, and the probability of decline increases with length of stay (Ang, Au, Yap, \& Ee, 2006). A search of the Pubmed database, using the key word combinations of 'elderly and activities of daily living (ADL)', revealed that many studies of both patient and organizational factors, affecting dependence in ADL have been conducted in the nursing home setting. Predictors to affect ADL were age (Peres, Verret, Alioum, \& BarbergerGateau, 2005), gender (Peres et al.), baseline ADL (Wu et al., 2000), incontinence (Wu et al.), pressure ulcers (Buttar, Blaum, \& Fries, 2001), delirium (McCusker, Cole, Dendukuri, Belzile, \& Primeau,

\footnotetext{
Address reprint requests to: Cho, Eunhee

Yonsei University College of Nursing, 134 Sinchon-dong, Seodaemun-gu, Seoul 120-752, Korea

Tel: +82-2-2228-3251 Fax:+82-2-392-5440 E-mail: ehcho@yuhs.ac
}

Received: May 3,2011 Revised: May 11,2011 Accepted: December 19,2011 
2001), and cognitive impairment (Barberger-Gateau, Fabrigoule, Amieva, Helmer, \& Dartigues, 2002). Organizational factors that were reported to affect patient dependence in ADL in nursing homes were ownership (Harrington, Woolhandler, Mullan, Carrillo, \& Himmelstein, 2001), number of beds (Rantz et al., 2004), licensed nursing hours (Horn, Buerhaus, Bergstrom, \& Smout, 2005), staffing levels (Bostick, Rantz, Flesner, \& Riggs, 2006), and registered nurse (RN) turnover (Collier \& Harrington, 2008).

Although these studies have contributed evidence regarding the factors that affect dependence in ADL in nursing homes, the latter institutions are not the only setting for long-term care of the elderly in South Korea. Long-term care hospitals (LTCHs) also provide such care services, but, so far, investigations in which they have been the focus are still lacking. LTCHs have no admission criteria (e.g., severity, degree of service needs), so the patients possess similar characteristics to those of patients in nursing homes (Lee, Park, Yoon, \& Song, 2007). However, the legal regulation of LTCH differ from those of nursing home, the context of LTCH may induce different result from nursing home, about impact factors on ADL. Legal regulations of LTCH in Korea include the obligatory presence of a medical doctor (MD) and higher nursing staff levels. The subject of the most previous studies of the factors affect dependence in ADL were nursing home and residents, therefore the study of LTCHs in Korea was required to compare with previous studies.

The purpose of this study was therefore to explore factors that have an impact on the ADL of older adults in Korean LTCHs. Determination of these factors could be useful in targeting intervention programs aimed at the maintenance and improvement of ADL in LTCHs.

\section{METHODS}

\section{Data sources}

This study is a secondary analysis of the Korean minimum data set (K-MDS) of patients and profiles of LTCHs from the Health Insurance Review and Assessment Service (HIRA). The K-MDS includes patients' clinical status and information regarding service use. The profile of LTCHs includes features of organizational characteristics. HIRA reviews the K-MDS of all LTCHs, and collects and monitors their profiles for reimbursement under the Korean National Health Insurance System.
This study received approval from HIRA research review committee with the data sources. The approval by the institutional review board (IRB) the Y University College of Nursing (2009-0020) was acquired.

\section{1) Korean minimum data set (K-MDS)}

In order to be reimbursed for per diem fees, all LTCHs in South Korea are required to report the K-MDS to HIRA on a monthly basis. This study used the K-MDS of patients who were hospitalized for at least 6 months between January and July 2008. The K-MDS was used to both determine patient classification for per diem fees and to monitor patient function and health status, and was collected monthly by RNs, following the guidance provided in "Manuals for assessing patients of long-term care hospitals." The K-MDS of LTCHs consisted of 11 categories with 50 items. The average weighted Kappa value for the items was .76 (Lee, Yoon, \& Jang, 2008).

\section{2) Hospital profile}

Hospital profiles from HIRA include organizational characteristics of LTCHs, such as ownership, location, number of beds, and staffing levels of doctors, RNs, nurse aides (NAs), and physical therapists The hospital profile for the period between January and July 2008 was used in this study. The change of ownership and location didn't occurred in this period. However, the number of beds and staffing level change occurred quarterly, the second quarter data used finally.

\section{Study sample}

The K-MDS and hospital profiles used information regarding patients in 638 LTCHs. Inclusion criteria were applicable at both patient and hospital levels, using patient and hospital characteristics.

The inclusion criteria for patients were hospitalization for 6 months or more (180 \pm 10 days) and age 65 years and older; any patients that were comatose were excluded. Patient baseline data were K-MDS of January and February 2008, and patient outcome data were K-MDS of June and July 2008.

At the hospital level, LTCHs ( $\mathrm{n}=131)$ opened after January 1, 2008 (operation period more than 7 months, at the time of last outcome measure: July 31. 2008), were excluded owing to their unstable operational status. LTCHs $(\mathrm{n}=21)$, as were those with missing staffing data. LTCHs $(\mathrm{n}=128)$ with fewer than 10 patients who met the inclusion 
criteria were also excluded, since fewer than 10 patients in any one hospital may not adequately represent the patient population of that hospital. The final study sample included 14,369 patients from 358 LTCHs.

Moineddin, Matheson, and Glazier (2007) recommend using 100 groups, with each group comprising at least 50 patients, in order to produce valid estimates for multilevel logistic regression models. The sample size of this study was adequate. Statistical power was calculated using G-Power program 3.1; 14,369 patients provide power of at least 95\%, with an alpha level of .05 when assuming a small effect size of .02 (Cohen, 1998).

\section{Study variables}

\section{1) Outcome variable}

The previous studies of ADL change tested ADL outcome after 3 or 6 months after baseline (Buttar et al., 2001; Phillips, Shen, Chen, \& Sherman, 2007) and the result of Phillips et al. reported better explanatory power in model after 6 month than 3 month. Therefore, the outcome variable of this study was the ADL score 6 months after baseline.

The ADL score in the K-MDS was the sum of 10 different items, which are each rated on a scale of $0-4$. The items were dressing, grooming (face), grooming (teeth), bathing, feeding, bed mobility, sitting up, transfer, ambulation, and going to the toilet. The ADL score ranged from 0 (totally independent) to 40 (totally dependent in all items). The Cronbach's co-efficient ( $\alpha$ ) of ADLs at baseline and after 6 months were .97 and .98 , respectively.

\section{2) Predicting variables}

The predictors were patient characteristics in baseline data from the K-MDS and hospital profile in January and February 2008. Predicting variables at both the patient and hospital levels were included. Those at the patient level included age, gender, baseline ADL score, frequency of physical therapy, delirium, behavioral problem, urinary problem, fecal incontinence and specific problems or treatment (e. g., acute problem, end-stage, pressure ulcer, tube or catheter) at the time of baseline. The baseline ADL included at predicting variable as a covariate, considering the many report that the baseline ADL impact on ADL change (Lee \& Rantz, 2008; Wu et al., 2000).

The frequency of physical therapy was measured in number of days of treatment received over the previous 7 days of baseline measure time. Measurements of delirium (no=no delirium, yes $=$ delir ium), behavioral problem (no=none, yes $=$ one or more behavioral symptoms of a total of 14 items, e. g., delusion, hallucination, agitation/aggression, depression, etc.), urinary problem (no = completely continent or voiding program, yes $=$ one or more episodes of incontinence and no management program), fecal incontinence (no = completely continent, yes = one or more episodes of incontinence), acute problem (no = none, yes $=$ one or more of fever, dehydration, vomiting, bleeding), end-stage (no = no end-stage, yes = end-stage), pressure ulcers (no = none, yes $=$ one or more ulcers beyond first-stage) and tube or catheter (no=none, yes $=\mathrm{L}$-tube, T-tube, urinary catheter, etc.) were also based on occurrences during the previous 7 days.

At the hospital level, the predicting variables were ownership, location, number of beds, and staffing levels obtained from the hospital profile. Staffing levels were calculated on the basis of the regulations of medical law (Korea Ministry of Goverment Legislation, 2010) on the manpower of the LTCHs. There are no regulations governing the proper number of physical therapists, so staffing levels were calculated by the number of physical therapists per 10 beds per hospital. The skill-mix ratio of nursing staff was calculated as the percentage of RNs out of the total nursing staff, which included both RNs and NAs.

The final predictors were included after considering multicollinearity, using variance inflation vectors (VIF). The VIF of skill-mix ratio was 24.0, so the variable was excluded.

\section{Data analysis}

Descriptive analysis was conducted for both patient and organizational characteristics. The ANOVA, t-test and Pearson's correlation used for comparison of ADL score at 6 months after baseline by patient and organization factors. A multilevel linear regression model was employed using predictors that were significant in ANOVA, a ttest and a Pearson's correlation test to explore patient and organizational factors that have an impact on ADL scores at 6 months.

Multilevel models were designed to analyze data generated from a hierarchical structure (e.g., patients nested within hospitals). In the present study, the first tier was the hospital level, in which the variables of organizational characteristics were aggregated, and the second tier was at the individual patient level. The SAS GLIMMIX pro- 
cedure was employed for multilevel linear regression analysis. The SAS version 9.1 was used for all analytical procedures.

\section{RESULTS}

\section{Characteristics of patients and organizations}

Most patients in LTCHs were between 65 and 85 years old (75.3\%), and the majority were female (78.2\%). Of the patients, $45.4 \%$ had ADL scores of 31-40 at baseline (with 40 indicating that the patient is totally dependent in all items). The frequency of physical therapy was 1.04 sessions per week on average; however, the majority of patients (77.5\%) did not receive any physical therapy. Patients experienced problems in the following proportions; delirium (25.1\%), behavioral problems (13.5\%), urinary incontinence (62.5\%), fecal incontinence (70.2\%), acute health problems with fever, dehydration, vomiting, or bleeding (6.8\%), end-stage (4.4\%), 8.2\% with pressure ulcers, and 19.3\% with a tube or catheter (Table 1).

Organizational characteristics were presented in Table 2. The majority of LTCHs (88.8\%) were private hospitals. LTCHs were evenly
Table 1. Patient Characteristics at Baseline

$(N=14,369)$

\begin{tabular}{lcc}
\hline Variables & & $\mathrm{n}(\%)$ \\
\hline Age (yr) & $65-84$ & $10,815(75.3)$ \\
& $\geq 85$ & $3,554(24.7)$ \\
Gean (SD) & $79.7(7.2)$ \\
& Male & $3,129(21.8)$ \\
Baseline score for ADLs & Female & $11,240(78.2)$ \\
& $0-10$ & $2,245(15.6)$ \\
& $11-20$ & $2,496(17.4)$ \\
& $21-30$ & $3,112(21.6)$ \\
Frequency of physical therapy & $31-40$ & $6,516(45.4)$ \\
per week & Mean (SD) & $25.9(12.5)$ \\
& 0 & $11,139(77.5)$ \\
Delirium & $1-4$ & $1,081(7.5)$ \\
Behavioral problems & $5-7$ & $2,149(15.0)$ \\
Urinary problems & Mean (SD) & $1.0(2.0)$ \\
Fecal incontinence & & $3,603(25.1)$ \\
Acute problems* & & $1,937(13.5)$ \\
End-stage & & $8,975(62.5)$ \\
Pressure ulcer & & $10,089(70.2)$ \\
Tube or catheter & & $978(6.8)$ \\
\hline & & $632(4.4)$ \\
Acute & & $1,182(8.2)$ \\
& & $2,768(19.3)$ \\
\hline
\end{tabular}

${ }^{*}$ Acute health problems: Fever, dehydration, vomiting, or bleeding. $\mathrm{ADL}=$ Activities of daily living.

Table 2. Organization Characteristics

\begin{tabular}{|c|c|c|c|c|}
\hline Variables & & & $\begin{array}{c}\text { Hospitals }(n=358) \\
n(\%)\end{array}$ & $\begin{array}{c}\text { Patients }(n=14,369) \\
n(\%)\end{array}$ \\
\hline \multirow[t]{2}{*}{ Ownership } & Public & & 40 (11.2) & $1,801(12.5)$ \\
\hline & Private & & $318(88.8)$ & $12,568(87.5)$ \\
\hline \multirow[t]{3}{*}{ Location } & Metropolitan & & $139(38.8)$ & $5,166(36.0)$ \\
\hline & Urban & & $107(29.9)$ & $4,516(31.4)$ \\
\hline & Rural & & $112(31.3)$ & $4,687(32.6)$ \\
\hline \multirow[t]{3}{*}{ Number of beds } & 30-99 beds & & $148(41.3)$ & $3,520(24.5)$ \\
\hline & $100-199$ beds & & $162(45.3)$ & $6,787(47.2)$ \\
\hline & $\geq 200$ beds & & $48(13.4)$ & $4,062(28.3)$ \\
\hline \multirow[t]{16}{*}{ Staffing level } & MDs per 40 beds & $<1$ & $139(38.8)$ & $6,626(46.1)$ \\
\hline & & $\geq 1$ & 219 (61.2) & $7,743(53.9)$ \\
\hline & & Mean (SD) & $1.09(0.23)$ & \\
\hline & Nurses per 6 beds & $<1$ & $246(68.7)$ & $9,819(68.3)$ \\
\hline & & $\geq 1$ & $112(31.3)$ & $4,550(31.7)$ \\
\hline & & Mean (SD) & $0.90(0.18)$ & \\
\hline & Skill-mix ratio of nursing staff & $<25$ & 14 (3.9) & $353(2.4)$ \\
\hline & & $25-49$ & $146(40.8)$ & $5,296(36.9)$ \\
\hline & & $50-74$ & $133(37.1)$ & $5,932(41.3)$ \\
\hline & & $\geq 75$ & $65(18.2)$ & $2,788(19.4)$ \\
\hline & & Mean (SD) & $55.32(19.08)$ & \\
\hline & Physical therapist per 10 beds & 0 & $8(2.2)$ & $180(1.2)$ \\
\hline & & $<0.25$ & $229(64.0)$ & $9,594(66.8)$ \\
\hline & & $0.25-0.49$ & 94 (26.3) & $3,550(24.7)$ \\
\hline & & $\geq 0.5$ & $27(7.5)$ & $1,045(7.3)$ \\
\hline & & Mean (SD) & $0.24(0.21)$ & \\
\hline
\end{tabular}

$\mathrm{MD}=$ Medical doctor 
distributed across metropolitan, urban, and rural areas, and most had fewer than 200 beds. At the staffing level, the mean of number MDs per 40 beds was $1.09( \pm 0.23)$, and approximately $40 \%$ of hospitals had less than one MD per 40 beds. The mean of number of nurses per 6 beds was $0.90( \pm 0.18)$, and most hospitals (68.7\%) had less than one nurse per 6 beds. The mean skill-mix ratio of the nursing staff, which was the proportion of RNs out of the entire nursing staff, which included both RNs and NAs, was 55.32 ( \pm 19.08$)$. At approximately $45 \%$ of hospitals, RNs constituted less than $50 \%$ of the nursing staff. Most hospitals had one or more physical therapists; however, the mean of number of physical therapists per 10 beds was less than 0.25 .

\section{Factors associated with ADL six months after baseline}

ADL six months after baseline varied by, or was correlated with, patient and organization characteristics except for ownership (e.g., public or private) (Table 3).

Multilevel linear regression showed that none of the organizational characteristics were significantly associated with the ADL of older adults after 6 months. Among the patient factors, age, baseline ADL score, frequency of physical therapy, urinary incontinence, fecal incontinence, pressure ulcers, and having a tube or catheter were significant. Patients who were older, had lower ADL score at baseline, urinary incontinence, fecal incontinence, pressure ulcers, or a tube or catheter were more likely to have a low ADL score after 6 months. Conversely, those patients who received more physical therapy at baseline were more likely to have a higher ADL six months after baseline (Table 4).

\section{DISCUSSION}

This study both examined the ADL of older adults admitted to Korean LTCHs, and explored patient and organizational factors that may have an impact on this ADL. We found that no organizational factor was significantly associated with the ADL of older adults. This is inconsistent with previous research, which has shown that for-profit ownership and higher staffing levels, in particular, more licensed nursing hours at nursing homes, affect the ADL of older adults (Rantz et al., 2004). Lee (2009) reported that ownership, number of beds, and staff turnover rate of organizations were related to deterioration in quality of service, including decline in ADL, in Korean LTCHs. In
Table 3. ADLs Score after 6 Months by Patient and Organizational Characteristics

\begin{tabular}{|c|c|c|c|c|}
\hline \multicolumn{2}{|l|}{ Variables } & Mean (SD) & Fort & $p$ \\
\hline \multicolumn{5}{|c|}{ Patient characteristics } \\
\hline \multicolumn{2}{|c|}{ Age } & & $0.04^{*}$ & $<.001$ \\
\hline \multirow[t]{2}{*}{ Gender } & Male & $24.5(12.83)$ & -8.88 & $<.001$ \\
\hline & Female & $26.8(12.3)$ & & \\
\hline \multicolumn{2}{|c|}{ Baseline ADL score } & & $0.83^{*}$ & $<.001$ \\
\hline \multicolumn{2}{|c|}{ Frequency of physical therapy } & & $0.03^{*}$ & $<.001$ \\
\hline \multirow[t]{2}{*}{ Delirium } & Yes & $29.2(11.1)$ & 17.34 & $<.001$ \\
\hline & No & $25.3(12.7)$ & & \\
\hline \multirow{2}{*}{$\begin{array}{c}\text { Behavioral } \\
\text { problems }\end{array}$} & Yes & $25.6(13.5)$ & -2.55 & .011 \\
\hline & No & $26.4(12.3)$ & & \\
\hline \multirow{2}{*}{$\begin{array}{l}\text { Urinary inconti- } \\
\text { nence }\end{array}$} & Yes & $30.1(10.3)$ & 49.2 & $<.001$ \\
\hline & No & $19.9(13.1)$ & & \\
\hline \multirow{2}{*}{$\begin{array}{l}\text { Fecal inconti- } \\
\text { nence }\end{array}$} & Yes & $30.9(9.9)$ & 80.7 & $<.001$ \\
\hline & No & $15.3(10.9)$ & & \\
\hline \multicolumn{2}{|c|}{ Acute problems Yes } & $31.2(10.5)$ & 14.9 & $<.001$ \\
\hline & No & $25.9(12.5)$ & & \\
\hline \multirow[t]{2}{*}{ End-stage } & Yes & $29.9(11.8)$ & 7.9 & $<.001$ \\
\hline & No & $26.1(12.5)$ & & \\
\hline \multirow[t]{2}{*}{ Pressure ulcers } & Yes & $35.1(7.9)$ & 37.5 & $<.001$ \\
\hline & No & $25.5(12.5)$ & & \\
\hline \multicolumn{2}{|c|}{ Tube or catheter Yes } & $33.5(10.0)$ & 40.3 & $<.001$ \\
\hline & No & $24.6(12.4)$ & & \\
\hline \multicolumn{5}{|c|}{ Organization characteristics } \\
\hline \multirow[t]{2}{*}{ Ownership } & Public & $26.0(12.7)$ & -1.12 & .265 \\
\hline & Private & $26.3(12.4)$ & & \\
\hline \multirow[t]{3}{*}{ Location } & Metropolitan & $27.5(12.1)$ & 63.16 & $<.001$ \\
\hline & Urban & 26.5 (12.4) & & \\
\hline & Rural & 24.7 (12.8) & & \\
\hline \multirow{3}{*}{$\begin{array}{l}\text { Number of } \\
\text { beds }\end{array}$} & $30-99$ & $26.7(12.4)$ & 10.66 & $<.001$ \\
\hline & $100-199$ & $26.5(12.4)$ & & \\
\hline & $\geq 200$ & $25.5(12.6)$ & & \\
\hline \multirow[t]{4}{*}{ Staffing level } & MDs per 40 beds & - & $0.03^{*}$ & $<.001$ \\
\hline & Nurses per 6 beds & - & $0.05^{*}$ & $<.001$ \\
\hline & Skill-mix ratio & - & $0.12^{*}$ & $<.001$ \\
\hline & $\begin{array}{l}\text { Physical therapists } \\
\text { per } 10 \text { beds }\end{array}$ & - & $0.08^{*}$ & $<.001$ \\
\hline
\end{tabular}

*Pearson's $r$.

$\mathrm{ADL}=$ Activities of daily living; $\mathrm{MD}=$ Medical doctor.

the acute setting, physician board-certification and RN staffing levels had an impact on patient outcome in intensive care units in Korea (Cho, Hwang, \& Kim, 2008). Spilsbury, Hewitt, Stirk, and Bowman (2011) pointed out an inconsistency with regard to the relationship between organizational factors and patient outcome, and proposed methodological consistency; Defining and measuring staffing and patient outcome.

There are potential explanations for the lack of a significant role for organizational factors in the ADL of older adults in LTCHs in this 
Table 4. Association of Patient and Organizational Characteristics with ADLs after Six Months

\begin{tabular}{|c|c|c|c|c|c|}
\hline Variables & & Estimate (b) & Standard error & $\mathrm{t}$ & $p$ \\
\hline Intercept & & 2.87 & 1.32 & 2.17 & .031 \\
\hline \multicolumn{6}{|l|}{ Patient characteristics } \\
\hline Age & & 0.02 & 0.01 & 3.08 & .002 \\
\hline Gender (Ref: Female=1) & Male & -0.17 & 0.13 & -1.26 & .208 \\
\hline Baseline ADL score & & 0.77 & 0.01 & 121.17 & $<.001$ \\
\hline Frequency of physical therapy & & -0.09 & 0.04 & -2.48 & .013 \\
\hline Delirium (Ref: No=1) & Yes & 0.27 & 0.15 & 1.78 & .075 \\
\hline Behavioral problems (Ref: $\mathrm{No}=1$ ) & Yes & 0.05 & 0.18 & 0.26 & .795 \\
\hline Urinary incontinence (Ref: $\mathrm{No}=1$ ) & Yes & 0.93 & 0.15 & 6.32 & $<.001$ \\
\hline Fecal incontinence (Ref: No=1) & Yes & 1.74 & 0.17 & 10.07 & $<.001$ \\
\hline Acute problems (Ref: No=1) & Yes & -0.16 & 0.23 & -0.68 & .495 \\
\hline End-stage (Ref: $\mathrm{No}=1$ ) & Yes & -0.48 & 0.31 & -1.58 & .114 \\
\hline Pressure ulcers (Ref: No=1) & Yes & 0.82 & 0.21 & 3.91 & $<.001$ \\
\hline Tube or catheter (Ref: No=1) & Yes & 1.34 & 0.16 & 8.26 & $<.001$ \\
\hline \multicolumn{6}{|l|}{ Organization characteristics } \\
\hline \multirow[t]{2}{*}{ Location (Ref: Rural =1) } & Metropolitan & 0.27 & 0.41 & 0.66 & .512 \\
\hline & Urban & -0.05 & 0.44 & -0.11 & .913 \\
\hline \multirow[t]{2}{*}{ Number of beds (Ref: $\geq 200=1$ ) } & $30-99$ & 0.34 & 0.53 & 0.65 & .514 \\
\hline & $100-199$ & -0.32 & 0.49 & -0.66 & .512 \\
\hline \multirow[t]{3}{*}{ Staffing level } & MDs per 40 beds & 0.33 & 0.78 & 0.42 & .672 \\
\hline & Nurses per 6 beds & -0.32 & 1.00 & -0.32 & .751 \\
\hline & Physical therapists per 10 beds & 0.08 & 0.84 & 0.09 & .925 \\
\hline
\end{tabular}

$\mathrm{ADL}=$ Activities of daily living; $\mathrm{MD}=$ Medical doctor.

study. Firstly, the inconsistent findings could be due to the difference between South Korea and Western countries in terms of staffing levels in long-term care settings. Centers for Medicare and Medicaid Services (2001) reported that a staffing level that does not meet the minimum staffing threshold cannot have a positive effect on patient outcomes. The levels of nursing staff of Korean LTCHs may be too low to have an effect on the ADL of older adults. Many LTCHs do not meet the minimum requirement for nurse staffing levels in South Korea, which according to law, is 40 patients per MD and six patients per nurse (Korea Ministry of Goverment Legislation, 2010). In the present study, the MD staffing level of LTCHs was 1.09 ( \pm 0.23$)$ per 40 patients, which meets minimum requirements. However, the level of nurse staffing was only $0.90( \pm 0.18)$ per six patients, on average, showing that many Korean LTCHs fall short of minimum nurse staffing level requirements.

Another possible explanation is the lack of availability of nursing interventions for maintaining and improving ADL, such as bladder and bowel training, in Korean LTCHs (Kim, Chang, Oh, \& Bae, 2003; Lee, Yoon, Kim, \& Kim, 2008). HIRA conducted surveys of nursing department directors in 514 LTCHs, as well as staff including MDs, RNs, and NAs in 20 LTCHs, in order to explore the services and ac- tivities available for quality management in these institutions (Lee et al.). The results showed that there was a lack of nursing interventions, clinical guidelines, and staff education around maintaining and improving patient ADL in LTCHs. In addition, almost half of the staff members (48.6\%) reported that the latter are the most deficient services provided in LTCHs, a deficiency they believe is due to low staffing levels and quality of staff. Therefore, these healthcare services may not be sufficient to have a positive impact on the ADL of older adults, regardless of the characteristics of the organizations themselves. The present study found that older adults receiving more physical therapy tend to have better ADL after 6 months. The provision of nursing interventions to maintain and improve ADL in older adults in LTCHs may therefore result in greater long-term improvements.

Conversely, patient characteristics were significantly associated with the ADL of older adults in this study, which was consistent with previous findings that older age, incontinence, pressure ulcers, and baseline ADL are independent predictors of poorer ADL (Wu et al., 2000). Importantly, Lee and Rantz (2008) reported that low ADL scores, incontinence, and pressure ulcers were the most important predictors of poor ADL scores at 3 months, which was consistent with the findings of the present study. The frequency of physical ther- 
apy was a factor that affected ADL in our study. Some investigations have reported the effect of rehabilitation for older adults in long-term care facilities and hospitals (Kim, Park, \& Han, 2010; Lee, Park, \& Park, 2005), and researchers have proposed criteria to identify patients at risk of an increase in ADL decline (Hong, Yi, \& Yi, 2007).

The absence of relationships between organizational characteristics and the ADL of older adults that was found in our study should not be interpreted as conclusive evidence that organizational characteristics do not affect the ADL of older adults in LTCHs since our study has limitations. First, detailed information regarding nursing staff such as RN hours for direct care, RN education level, and RN turnover is not available in the hospital profiles obtained from HIRA. Therefore, the examination of the effects of nursing staff on the ADL of older adults in LTCHs may have limitations. Secondly, the variables used in this study were limited to those in the K-MDS, meaning that potential factors, such as the types, frequency, and intensity of nursing interventions to maintain and improve the ADL of older adults in LTCHs may have been excluded.

It is essential to consider that some of statistically significant findings in this study can be due to a large sample size although they are not clinically significant. This study suggest that patients with older age, urinary and fecal incontinence, pressure ulcer and tube or catheter, as a risk group, should managed more intensively to prevent more dependence in $\mathrm{ADL}$ and physical therapy should encouraged in the case of need. The development of nursing intervention for improvement of $\mathrm{ADL}$ in $\mathrm{LTCH}$ is required. The repeated studies of relationship of staffing level and ADL change, and those of the effective staffing level for improvement of ADL could support the effort of organizational level.

\section{CONCLUSIONS}

Among older adults resident in Korean LTCHs, those who were older, had low ADL at baseline, urinary incontinence, fecal incontinence, pressure ulcers, and a tube or catheter were more likely to exhibit low ADL after 6 months. However, those who received more physical therapy were more likely to have improved ADL at this time point. None of the organizational characteristics were significantly associated with the ADL of the study population.

This is the first study to explore the ADL of older adults and associated factors of ADL using national data for LTCHs in South Korea.
Thus, the findings of this study can easily be extrapolated across the same population in all South Korean LTCHs, and may be useful in identifying high-risk groups of older adults in LTCHs who are vulnerable to further loss of ADL.

Our results suggest that, in order to maintain and improve the ADL of older adults in LTCHs, we should develop strategies to prevent urinary incontinence, fecal incontinence, and pressure ulcers, and reduce the introduction of unnecessary tubes or catheters should be developed, in addition to providing adequate physical therapy. A risk-factor assessment should be performed on admission or shortly afterwards, to identify high risk patients. The rehabilitation programs for ADLs and preventive care plans to minimize risk factors are also required.

Additional studies should include more detailed information regarding nursing staff, including RN hours for direct care, RN education level, and RN turnover, and it is suggested that investigations examining nursing interventions for maintaining and improving ADL in older adults in Korean LTCHs are conducted. Future studies should include these nursing intervention variables in order to properly and fully explore the effects of organizational characteristics on the ADL of older adults in Korean LTCHs.

\section{REFERENCES}

Ang, Y. H., Au, S. Y. L., Yap, L. K. P., \& Ee, C. H. (2006). Functional decline of the elderly in a nursing home. Singapore Medical Journal, 47, 219-224.

Barberger-Gateau, P., Fabrigoule, C., Amieva, H., Helmer, C., \& Dartigues, J. F. (2002). The disablement process: A conceptual framework for dementia-associated disability. Dementia \& Geriatric Cognitive Disorders, 13(2), 60-66. doi: 10.1159/000048635

Bostick, J. E., Rantz, M. J., Flesner, M. K., \& Riggs, C. J. (2006). Systematic review of studies of staffing and quality in nursing homes. Journal of the American Medical Directors Association, 7(6), 366-376. doi: 10.1016/ j.jamda.2006.01.024

Buttar, A., Blaum, C., \& Fries, B. (2001). Clinical characteristics and six-month outcomes of nursing home residents with low activities of daily living dependency. The Journals of Gerontology, 56A(5), M292-M297.

Centers for Medicare and Medicaid Services. (2001). Report to congress: Appropriateness of minimum nurse staffing ratios in nursing homes. Phase II Final report. Baltimore, MD: Author.

Cho, S. H., Hwang, J. H., \& Kim, J. Y. (2008). Nurse staffing and patient mortality in intensive care units. Nursing Research, 57, 322-330. doi: 10.1097/ 01.NNR.0000313498.17777.71

Cohen, J. (1998). Statistical power analysis for the behavioral science (2nd ed.). New Jersey: Lawrence Erlbaum Associates.

Collier, E., \& Harrington, C. (2008). Staffing characteristics, turnover rates, and quality of resident care in nursing facilities. Research in Gerontologi- 
cal Nursing, 1, 157-170. doi: 10.3928/00220124-20091301-03

Harrington, C., Woolhandler, S., Mullan, J., Carrillo, H., \& Himmelstein, D. U. (2001). Does investor ownership of nursing homes compromise the quality of care? American Journal of Public Health, 91, 1452-1455.

Hong, S. P., Yi, J. J., \& Yi, S. W. (2007). A factors related to activities of daily living (ADL) among patients in geriatric hospitals. Journal of Korean Society of Occupational Therapy, 15(2), 79-89.

Horn, S. D., Buerhaus, P., Bergstrom, N., \& Smout, R. J. (2005). RN staffing time and outcomes of long-stay nursing home residents: Pressure ulcers and other adverse outcomes are less likely as RNs spend more time on direct patient care. American Journal of Nursing, 105(11), 58-70; quiz 71.

Kim, E. K., Chang, H. S., Oh, J. H., \& Bae, S. K. (2003). Reserch on the actual condition and operation plan of long-term care hospitals. Seoul: Korean Health Industry Development Institute.

Kim, S. M., Park, J. Y., \& Han, C. H. (2010). Influential factors on rehabilitation exercise practice in elderly limited activities of daily-living: An analysis based on the theory of planned behavior. Journal of Korea Contents Society, 10, 271-281.

Korea Development Institute. (2010). Challenges of the long-term care insurance. Symposium conducted at the meeting of the Korea Development Institute. Seoul: Author.

Korea Ministry of Goverment Legislation. (2010). Medical treatment law. Retrieved December 1, 2010, from http://wwwlaw.go.kr/main.htm

Korea National Statistical Office. (2011). Estimated population by age. Retrieved July 1, 2011, from http://kosis.kr/themes/themes_02List.jsp\# jsClick

Lee, C. I., Park, D. M., \& Park, R. J. (2005). The effect of muscle enforcement exercise program on posture balance of the institution old. Journal of Dae-gu University, 1, 539-565.

Lee, J., \& Rantz, M. J. (2008). Admission factors influencing activities of daily living in nursing home residents admitted from acute care hospitals. Journal of Korean Gerontological Nursing, 10(1), 68-76.

Lee, J. Y., Yoon, J. Y., \& Jang, S. R. (2008). A study of validity and reliability of a patient assessment instrument for long-term care hospitals. Journal of Korean Gerontological Nursing, 10(1), 7-19.
Lee, J. Y., Yoon, J. Y., Kim, A. R., \& Kim, C. M. (2008). Development of quality management system and indicators of long term care hospitals. Seoul: Health Insurance Review and Assessment Service.

Lee, S. H. (2009). Multi-level analysis of factors related to quality of services in long-term care hospitals. Journal of Korean Academy of Nursing, 39, 409-421. doi: 10.4040/jkan.2009.39.3.409

Lee, S. Y., Park, E. K., Yoon, J. Y., \& Song, S. H. (2007). The current status of long-term care hospital. Seoul: Health Insurance Review \& Assessment Service.

McCusker, J., Cole, M., Dendukuri, N., Belzile, E., \& Primeau, F. (2001). Delirium in older medical inpatients and subsequent cognitive and functional status: A prospective study. Canadian Medical Association Journal, 165, 575-583.

Moineddin, R., Matheson, F. I., \& Glazier, R. H. (2007). A simulation study of sample size for multilevel logistic regression models. BMC Medical Research Methodology, 7, 1-10. doi: 10.1186/1471-2288-7-34

Morris, J. N., Murphy, K., \& Nonemaker, S. (2004). RAI-FC assessment manual version 2.0. Baltimore: Center for Medicare and Medicaid Services.

Peres, K., Verret, C., Alioum, A., \& Barberger-Gateau, P. (2005). The disablement process: Factors associated with progression of disability and recovery in French elderly people. Disability \& Rehabilitation, 27(5), 263-276. doi: 10.1080/ 09638280400006515

Phillips, C. D., Shen, R., Chen, M., \& Sherman, M. (2007). Evaluating nursing home performance indicators: An illustration exploring the impact of facilities on ADL change. The Gerontolotist, 47, 683-689.

Rantz, M. J., Hicks, L., Grando, V., Petroski, G. F., Madsen, R. W., Mehr, D. R., et al. (2004). Nursing home quality, cost, staffing, and staff mix. Gerontologist, 44(1), 24-38. doi: 10.1093/geront/44.1.24

Spilsbury, K., Hewitt, C., Stirk, L., \& Bowman, C. (2011). The relationship between nurse staffing and quality of care in nursing homes: A systematic review. International Journal of Nursing Studies, 48, 732-750. doi: 10.1016/j.ijnurstu.2011.02.014

Wu, A. W., Yasui, Y., Alzola, C., Galanos, A. N., Tsevat, J., Phillips, R. S., et al. (2000). Predicting functional status outcomes in hospitalized patients aged 80 years and older. Journal of the American Geriatrics Society, 48(5 Suppl), S6-S15. 